\title{
Promising Digital Schools: An Essential Need for an Educational Revolution
}

\author{
Fouad Mounier Yehya ${ }^{1 \star}$
}

\begin{abstract}
${ }^{1}$ Educational Research Laboratory- (LRE- Laboratoire de recherche en éducation), Faculty of education, Saint- Joseph University of Beirut, LEBANON ^Corresponding Author: fouad.yehia@usj.edu.lb
\end{abstract}

Citation: Yehya, F. M. (2021). Promising Digital Schools: An Essential Need for an Educational Revolution. Pedagogical Research, 6(3), em0099. https://doi.org/10.29333/pr/11061

\section{ARTICLE INFO}

Received: 12 Nov. 2020

Accepted: 9 Feb. 2021

\begin{abstract}
This paper endeavors to propose a clear framework to show how the Lebanese traditional schools will be transformed to digital schools to benefit from digital technology. Digitalization is prompting education at a very fast pace. Educational institutions are in vital need of technology implementations to stay digitally relevant to Netgeneration learners. Though many schools have digital initiatives and plans, the implementation of these up to a well-studied framework is something many institutions still lack. This study adopts the instructional design theory, which aims to propose a clear technology implementation framework to promote schools' digital transformation.

The study emphasizes that schools are in need to deal with a well-defined framework in their establishment for digital institutions and proposes a digital framework for schools to implement educational technology tools and strategies to gain the benefits attached to technological progress.

The suggested framework highlights the need for mutual interaction between schools' visions, teachers' professional development, some appropriate tools, learners' beliefs, and the learning society's support in guiding schools to attain the opportunities of digitalization in reforming education. Researchers, policymakers, and educators need to contribute to this developed framework and identify strengths, weaknesses, opportunities, and threats (SWOT analysis) of the suggested model on schools' digitalization process. However, additional research should be conducted regarding the impact of the model on enhancing the educational revolution. Hence, a call is made for researchers to continue testing the model in different contexts with the intent of refining it.
\end{abstract}

Keywords: digitalization framework, digitalization, digital school, digital technology, educational transformation

\section{INTRODUCTION}

Digital Technology is now an important integral aspect for the learning experience (Selwyn, 2016). Educational technology tools have become increasingly powerful and available for teachers and learners in the past three decades (Ross, 2020). It is the reform of the traditional information types (texts, sounds, visuals, videos, and other data from various sources) into the digital language (Wang \& Guo, 2017). It serves as a crucial powerful tool in the process of knowledge propagation and distribution to educate and shape young minds in the current digital age.

Educators, schools, and policymakers must create new opportunities through these technologies to improve the conventional teaching/learning experiences in traditional schools. This calls to alert the way in which the learning environment perceives education to improve the quality of education in schools, and prepare learners for the twenty-first-century requirements. Several experiential studies in recent years investigated the positive impact of digital technologies on effective learning (Kryukov \& Gorin, 2017; Niculescu, 2019). Educators from all grade-levels are coming to realize the benefits of technology as a vital element of learners' education and a transformer to the ways learners learn and experience (Yehya, 2019). Consequently, educational systems must be significantly moved forward towards digitalization in education due to the emergence of advanced technologies and globalization.

Despite the innovative potential and the usefulness of digital technologies in the educational setting, their implementations in meaningful learning do not occur spontaneously without complications. Digitalization is facing various obstacles at different levels that hinder its adoption in schools. Many ministries of education concentrate their potentials on hardware and lack the importance of infrastructures to welcome technological development. They do not reflect a clear vision on digitalization and an effective response towards instructors' professional development. Consequently, educators lack the vital meaning of digital literacy. They reflect low confidence and weak competencies to implement advanced digital tools and benefit from the communication channels of the social media platforms (Yehya et al., 2018). Their negative attitude towards digital tools and the 
effectiveness of their techniques lead to high resistance to accept digitalization and its impact on developing learners' achievement in their learning environment.

Accordingly, policymakers and educators need to show the importance of digital learning beyond the hardware and the expanded definition of the learning management systems (Yehya et al., 2018). Educators must show awareness of radical changes to their curricula, instructions, assessments, and classroom management in the presence of educational digital technology tools. Consequently, specific digital strategies in schools and the development of a well-fit framework must be evolved in response to the significant convergence towards digitalization in education and schools.

The status of Lebanese schools is not far away from digitalization barriers. During the COVID-19 epidemic, many of the digitalization processes in education have been held in Lebanon but the effectiveness of these measures was not assessed because of the lack of a methodological basis. The efforts made by the policymakers in technology investments for Lebanese educational systems are not sufficient to achieve the desired digitalized schools. The majority of Lebanese schools fail to be engaged in the digital age and to implement educational technology appropriately and effectively (Yehya, 2019). Schools' difficulties to implement ICT have continued to run during the process of adopting and using these technologies at the levels of learners, teachers, communities, and educational policymakers (Yehya et al., 2018).

In the context of this situation, the question that arises is: "How will the Lebanese traditional secondary schools be transformed to digital schools in order to benefit from the potential of digital technology?" Hence, the present paper aims to answer this question by providing a research-based model for schools to reflect on, to identify what hurdles influence the intentions of digitalizing to understand and improve their practices, and to achieve sustainable pedagogical improvements with the help of digital technologies. Therefore, the paper will adopt a descriptive research design to highlight the effectiveness of some digital tools and platforms. Also, it will rely on the design theory in promoting an appropriate digitalization framework assisting educators in improving the future and the quality of digital schools in the digital era.

The following conceptual framework, based on the review of the literature, will describe some appropriate digitalization tools, illustrate some digitalization models, and relate the main concepts necessary to answer the research question.

\section{CONCEPTUAL FRAMEWORK}

The digitalization of education has become a powerful trend in terms of reformation and modernization of the global educational environment. According to Ordov et al. (2019), the digitalization of the educational process is of particular importance since education can be considered the basis for the development of the economy and the achievement of the planned strategic goals. It refers to the use of desktop computers, mobile devices, the Internet, online courses, smartphones, cameras, interactive whiteboards, software applications, and other digital technologies to teach students of all ages (Machekhina, 2017). The road to digitalization is long and educators have to invest in a new digital technologies' curriculum and the provision of equipment and teacher professional development to support this goal (Masters, 2018). The digitalization of education needs investment in technology infrastructure and IT systems as it addresses a variety of new technological problems as software, computer viruses, and the privacy of information. Besides, the digitalization of education needs a shift to digital literacy through digital schools where learners and teachers can get relevant interactive information on their digital devices to extend performance and outputs. Hence, digital schools are the need in this educational revolution towards digitalization in education to ensure that all learners have the opportunity to become digitally capable individuals.

In this context, education policymakers, school principals, and leaders should heavily apply their potentials to transform traditional schools into digital schools to benefit from the potentials of ICT in enhancing learning and curriculum digitalization. So, education policymakers, school principals, and leaders should rely on the dynamic relationships between the digital competencies of school leaders, and the appropriate technology software that interact in well-defined models to facilitate schools' digitalization. According to Tang (2016), and Chun, Kern, and Smith (2016), digital schools serve to instruct learners through communicating social tools and multimedia including audios, videos, and graphics rather than using the traditional faceto-face modality to meet the needs of the net generation learners. Various technology tools exist to enhance schools' digital transformation. Managing diverse aspects of schools' digitalization starts with the policymakers' and educators' awareness of learning management systems to design personalized learning paths for learners. Schools should learn to harness learning processes that modify the role of teachers and fit the expectations and the needs of digital learners. They should adopt the best applications of technology to minimize costs.

The literature reviewed investigated and described some of the appropriate instructional and learning management software to elucidate digital transformation. Learning platforms are usually referred to as VLEs (virtual learning environments), LMSs (learning management systems), or LCMSs (learning content management systems). These terms are often used interchangeably, and despite the differences between the mentioned platforms, they have many features in common.

The use of a learning platform as one of the main "digital factories" is reforming and revolutionizing the ways of technology commercialization (Ordov et al., 2019). Virtual learning environments, or VLEs, are used to simulate traditional face-to-face classroom activities and facilitate teaching and learning with a strong collaborative component. Examples of VLEs are Moodle (http://moodle.org/) and Blackboard (http://www.blackboard.com/).

The learning management system (LMS) solution facilitates the delivery and management of all learning offerings, including online learning, virtual classrooms, and instructor-led courses. It contributes to an online digital curriculum that empowers teachers by saving them time with planning and grading so they can spend more time with their learners. It automates the learning course and easily delivers training, manages learners, and keeps track of their progress and performance across training activities, 
which reduces administrative overhead. (Ghirardini, 2011; Atan et al., 2008). Most LMSs support meta-data and content sharing standards such as Shareable Content Object Reference Model (SCORM), Institute of Electrical and Electronics Engineers (IEEE), Learning Object Metadata (LOM), Integrated Management System (IMS), and Aviation Industry Computer-Based Training Committee (AICC) (Pireva, Imran \& Dalipi, 2015; Fallon\& Brown, 2016). Courses are hosted and uploaded to the Learning Management System platform to become easily accessible for remote learners. The role of a Learning Management System (LMS) is beneficial for an educational institution in the sense it provides effective ways to store, manage, share, arrange digital academic resources and track online learning (Rashida, 2018), as well as to make educators capable of monitoring learners' progress and performance (Khan et al., 2017). So, LMS software allows educators to gather all Big Data in one location and helps in administration, documentation, tracking, and recording. LMSs are either free or need upgrades to offer more advanced support options and user-friendly features.

Massive Open Online Courses (MOOCs) are free Web-based distance learning programs that are hosted on the LMS and some MOOCs are examples of non-free platforms. They are designed for the participation of large numbers of geographically detached students (Stepan, 2013). The most familiar MOOCs leading the market of education today are: Coursera (https://www.coursera.org/), Udacity (http://www.udacity.com/), edX (http://www.edx.org/), and Khan Academy (www.khanacademy.org) that deliver high-quality educational content across multiple disciplines (Pireva et al., 2015). Nonetheless, Khan Academy is an example of a non-profit association that was hypothesized to build a range of online tools. This platform provides on its website, or on the Khan Academy's YouTube ${ }^{\mathrm{TM}}$ channel, an advanced learning analytics module with useful visualizations (Ruipérez-Valiente et al., 2015). The Khan Academy platform enables powerful on-line courses in which lessons are produced in the form of videos, interactive activities, and challenges. Students can watch videos and solve supplementary practice exercises to understand various lessons and concepts more easily. Also, teachers can make use of Khan Academy to supplement the teaching process and provide extra content to learners to enhance learning.

Furthermore, Google classroom is another example of free learning platforms. Google Classroom, the free web service digitalization tool, is a cloud-based learning management system and a part of Google Apps for Education. Google Classroom facilitates interaction by the way of sharing files between the enrolled instructors and learners who can access the platform from computers, tablets, and smartphones. Google Classroom merges between different google products. It connects Google Drive for assignment creation and distribution, Google Docs, Sheets and Slides for writing, Gmail for communication, and Google Calendar for scheduling in one platform. At this point, teachers can create online classrooms for sharing the learning materials for downloading and viewing and learners can post and submit their queries on the lessons taught and receive answers from teachers and other learners. Besides, instructors can post additional resources to be reviewed by the learner at any time and to post assignments in a paperless form to be graded and keep the track of learners' progress. Moreover, it is essential to encourage learners to communicate and collaborate using peer-to-peer feedback to explain their thoughts and offer suggestions regarding the writing content, scientific hypotheses, or creative ideas.

Seesaw is a friendly learning platform to keep digital portfolios of student work, including commenting on student submissions. Seesaw provides opportunities for users to securely store their photos, videos, drawings, text notes, links, and projects in the cloud through which parents can access their work. It allows teachers to push assignments out to students to individualize instruction and empowers students to independently document what they are learning and perceiving at school by submitting a video of themselves working on a problem-solving task, snapping a picture of a paragraph they wrote, recording themselves reading, or uploading a file to validate their learning. Thus, the seesaw tool can facilitate communication with learners' families and subsequently, it plays an essential role in reforming the learning environment of digital schools.

Furthermore, the digitalization of schools can benefit from the learning portal that acts as a gateway between users - the learners - and the learning content. Though learning management systems and learning portals (LP) are often used interchangeably, there is a difference between them. A learning portal is an online hub of content related to learning and performance. It includes all the LMS features; however, it is also a place that consists of informal learning courses and interactive applications such as forums, wikis, FAQs, and blogs that facilitate collaboration to promote the content. EPathshala, as an example, is a portal initiated by the Ministry of Human Resource Development and the National Council of Educational Research and Training (NCERT) (Saha \& Mukhopadhyay, 2016). It was launched in November 2015 as one of the initiatives of digitalizing education in India. Epathshala is a massive educational platform that hosts resources for teachers, students, parents, researchers, and educators (Sharma, 2019). EPathshala learning portal allows teachers to design personalized learning paths for their learners to overcome their needs. The learners in their turn can search and get access to all the required material, including interactive textbooks, audios, videos, periodicals, and a variety of other print and non-print materials. Additionally, EPathshala materials can be downloaded for offline use with absolutely no limits on downloads. Moreover, EPathshala allows learners and teachers to carry many books as their device supports. Thus, learning portals are just another facet of the same LMSs that donate customized overall learning paths and experiences to make progress in digital learning and school digital transformations. Educational institutions can personalize their learning portal features and create engaging digital classes for their learners.

Despite the importance of all the previous Learning Management Systems and learning portals, the process of digitalization remains incomplete if learners' assessment is not taken into consideration. The transformation into digital schools needs to review the assessment strategies and to follow learners' progress. Assessment should give a good improvement for learners' competencies and learners' opportunities to manage and know their learning (Brown\& Abeywickrama, 2010). According to Yulia and Susilowati (2020, January) teachers and learners positively responded to digitize their learning assessment to accommodate both their critical thinking and creativity. Kahoot is one of the platforms that can be used for this process. It is a game-based learning platform where learners can sit for multiple-choice quizzes and learn via games. With this digital tool that can be accessed via a web browser, the material can be projected in the classroom and learners can answer the questions using their cell phones, tablets, and computers. So learners are playing and learning at the same time. Thus, a game-based learning platform can enhance 


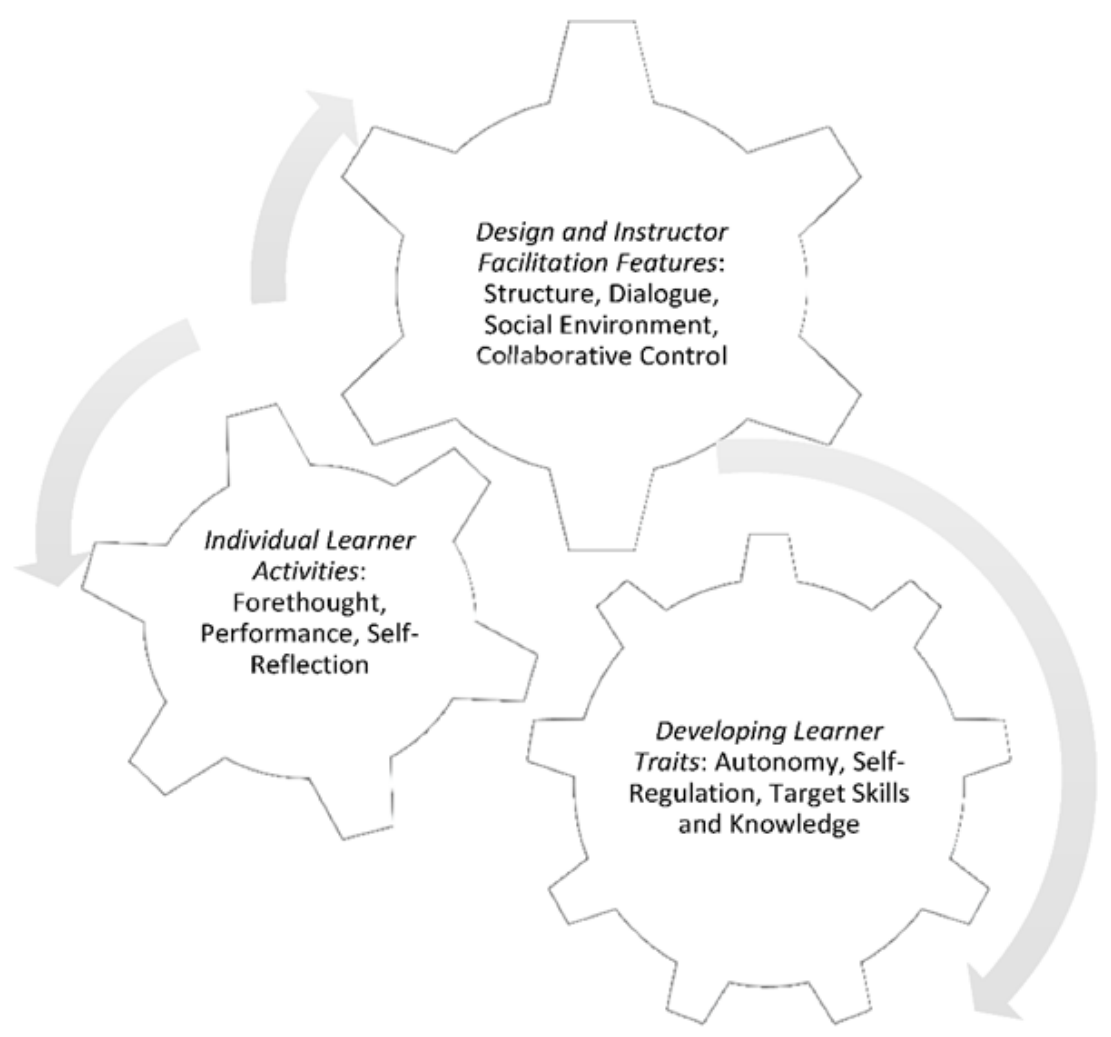

Figure 1. Model of e-learning and e-Teaching adopted from Andrade (2015)

learner's engagement and create a dynamic, social, and fun educational environment. It is vital to facilitate the process of transformation into digital schools.

Moreover, the literature reviewed pointed out the role of the school principals and leaders to support the work in leading for digitalization. Their digital competencies to lead strategically for digitalization and pedagogical development appears to be a key factor (Lindqvist \& Pettersson, 2019). Consequently, professional development (PD) seems to be needed for school leaders to understand and conceptualize digitalization. Thus, training related to implementing digital tools, such as LMS, that are purchased by the organization and expected by faculties to use in their courses facilitates the digitalization process.

Consequently, the schools' digitalization process cannot be attained and improved away from well-organized transformation models that combine schools' visions, individual professional development, pedagogical practices, and appropriate digital resources as main elements to improve schools and working practices with digital technology (Ilomäki \& Lakkala, 2018). In this context, the $=$ the literature reviewed revealed a large body of research models about enhancing the digitalization of institutions or e-Learning in the school setting. Lei et al. (2013) constructed the Cyber-Physical Systems (CPSs) for a smart learning environment (SLE) in universities to provide a reliable and productive learning environment. The model stressed the importance of computation, communication, and control components that are tightly integrated to insert and manipulate cyber/physical/information quantities. Lei et al. (2013) described the technical construction of the model as well as the long-time operation as a major technical challenge in its construction. In addition to that, the CPSs model lacks the importance of human interaction in enhancing the digital learning environment. Similarly, Coccoli et al. (2014) provide the model of a smarter university that acts in the context of smart cities, which offer smart facilities and applications to their citizens to improve and boost their quality of life. Coccoli Model represents a shared vision among the various stakeholders (i.e., teachers, students, administrations, nonprofit organizations, research institutions, citizens, industries, etc.). It concentrates on learners' and instructors' technical skills in a well-organized administration ready to admit any technical support. But this model lacks developing policies to encourage the cooperation between the policymakers and the users. Besides, it lacks the impact of the learners' socioeconomic status in offering appropriate tools on the digitalization transformation and technological learning process.

Andrade (2015) in the paper entitled "Effective eLearning and e-Teaching - A Theoretical Model" submitted a theoretical model to enhance digital learning. This model is illustrated in Figure 1.

Andrade's model reveals the integration between three required facets to enhance online learning. The first is related to the individual learning where learners are engaged in planning (goal-setting), performance (strategy application and monitoring), and self-reflection (review of progress). The second facet is related to the design of the organized content and facilities that give learners the opportunity to use a social environment facilitated by the instructor in order to interact, communicate and collaborate on tasks with other instructors and peers. The third facet depends on the features of the previous two facets to gradually develop the learner's autonomy, self-regulation, and targeted skills and knowledge. Thus, learners can apply what they are learning and reflect on their learning to improve the online learning experience. Even though this model provides learners with the structure and the potential to improve their strategies and learning in a technology-based distance course, it does not highlight the role of the instructor in teaching. In fact, it limits the role of the instructor in assessment and grading. Additionally, this model 
highlights the importance of social interaction or learning from others, but it fails to address the importance of interaction between the policymakers, the stakeholders, and the emergence of the digital infrastructure in designing digital learning in addition to the role of the learning society in accepting the digital transformation.

To conclude, the revealed models do not address the necessary role of human interaction in developing strategies for the digitalization process. They do not mention the role of the collaboration between the IT professionals and educators to promote digitalization and innovation across the institution to support and assist the institution's inclusive vision achievement. Thus, there is a need for a new developed dynamic framework that may shift the focus towards the importance of the relationship between the digital infrastructure and the interaction with the learners' social environment and all the human committees responsible for the success of the digitalization process that may cover the digitalization costs. But is this relevant? The coming methodological framework section will provide an answer.

\section{METHODOLOGICAL FRAMEWORK}

The coming methodological framework will reveal the research design and the approaches to collect data for analysis and interpretation.

\section{Research Design}

For this study, a comprehensive literature review of digital tools and models of digitalization was conducted using online library databases on Education Resources Information Center (ERIC), Google Scholar, Arab Educational Information Network (Shamaa), Education Full Text, and the Directory of Open Access Journals (DOAJ). Database was used to search for the following keywords: school digitalization; models of digitalization; assessment software; role of Learning Management Systems in digitalization; MOOCS for digitalization; Professional Development; digitalization of curricula, and so on. Thus, the study highlights some digital tools and barriers to their implementations. Besides, it employs the instructional-design theory to identify a transitional framework towards digital schools. It is a design-oriented research focusing on the suggested components to make the design more directly useful to promote schools' digital transformation. Moreover, it identifies the components of the framework needed for the transformation of the traditional school into a digital school to provide more guidelines for schools to overcome some barriers that delay achievement of digitalization goals in a better way.

\section{Data Collection}

The research relies on the review of the literature to collect data concerning useful digital tools to increase educators' awareness towards digital literacy. Some popular digital tools for facilitating the transformation into digital schools were identified and explored. The context of implementing these tools was analyzed. Also, data concerning the characteristics and dimensions of the framework was managed. The components were determined and classified and the limitations of the digital transformation were identified and explained. Finally, the suggested framework was designed, reviewed, and then conducted.

The coming section "Results and Discussions" will show in detail the suggested framework for the traditional schools' reforming.

\section{RESULTS AND DISCUSSIONS}

Schools should respond to digitalization rapidly and effectively to gain its benefits and develop strategies to overcome the challenges initiated by new technological changes during the pandemics and after it ends. Digitalizing education is a living environment that opens up new opportunities: learning at any convenient time, continuing education, etc. (Bilyalova et al., 2019). However, research shows that digitalization is a complex process requiring large-scale transformative changes (Holmgren et al., 2017). Such changes call for dynamic interaction between the learning community, school leaders, and policymakers. Changes include motivating learners, digitalizing curriculum, extending curriculum objectives, engaging learners, and offering "education for the $21^{\text {st }}$ century". So, transformative changes to digital school need several interacting keys that lead the digitalization progress.

The following section in the current endeavor reveals the results in the context to propose finally a framework to guide the transformative change from the traditional schools to digital schools. This framework, as shown in Figure 2, relies on: 1digitalizing schools' visions and strategies; 2- digital resources and expertise development; 3- learners' motivations and potentials; and 4- social and parents' awareness as four interacting key elements necessary to attain successfully digital transformation.

In the following part, the four related key elements of the suggested framework will be explained (See Figure 2). 


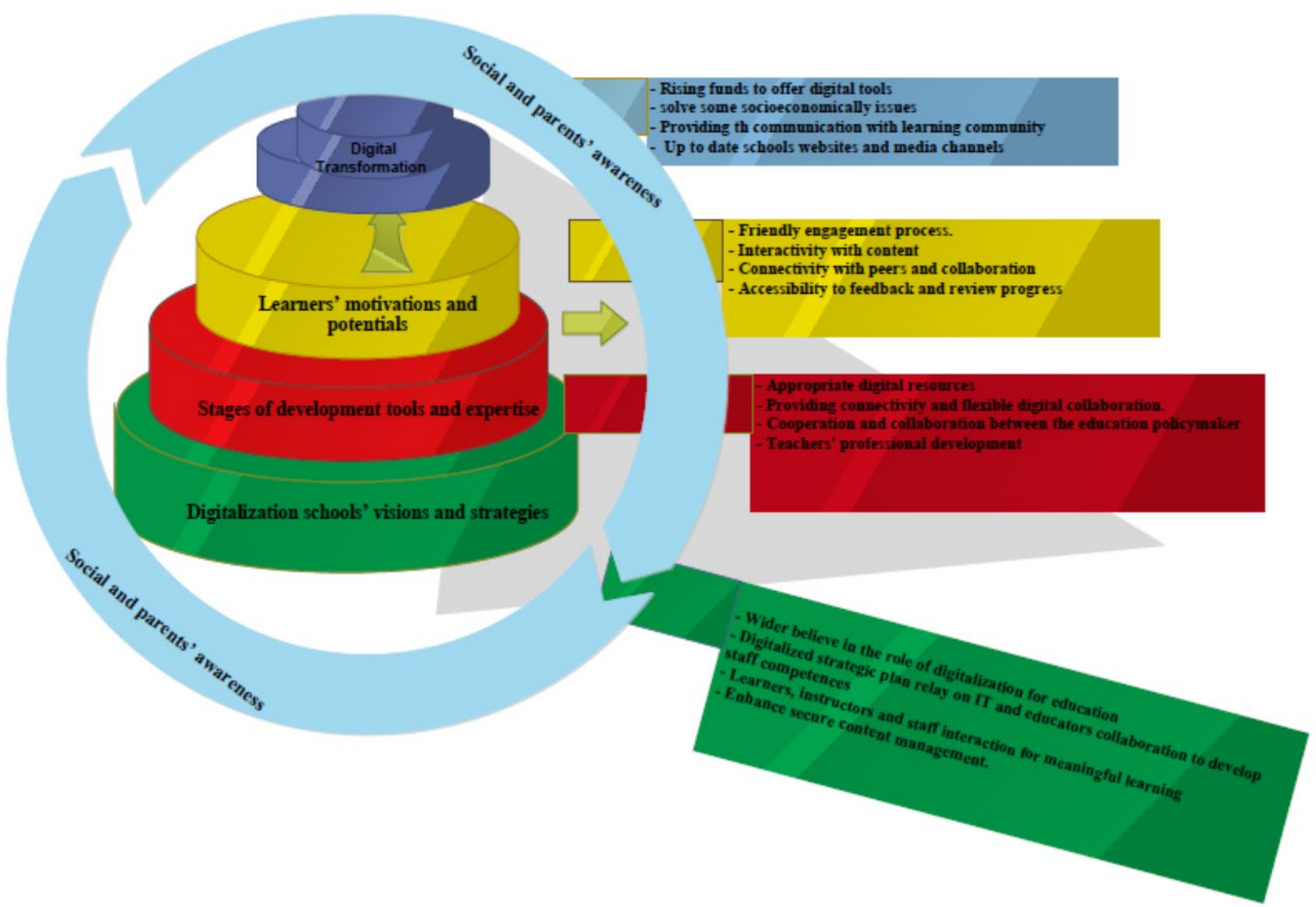

Figure 2. Digitalization framework for Schools revolution

\section{Digitalizing Schools' Visions and Strategies}

What is theoretically and practically meant by digitalization will be influenced by schools' vision regarding their budget plan, professional development, and organizational change. Schools' visions, the solid ground for any transformational change, should offer the necessary infrastructure for digitalization strategies and implement full potentials on the teachers' professional development in building their digital literacy awareness and understanding for digitalization and its transformational effects (Schleicher, 2012). Schools' visions should believe in the wider role of digitalization for education in all-school sections without just focusing on attaining the modern technology tools for business processes.

Digitalization that is not rooted in the digitalization strategic plan and methods developed by the policymakers/ educators to build a digital school can fail to transform practice and enhance students' learning (Pettersson, 2020). School administrators and teachers can support the development of a digital privacy policy for the school community, provide professional development about digital privacy and security, and monitor data access to protect the personal information of their learners, teachers, and other employees.

Consequently, the school's plan must activate the essential role of the IT section and upgrade its potential to attain maintainable outcomes. The school IT section should not be an isolated sector dealing only with technical issues. The technology department should provide insight into the future of digital school and suggest some guidelines for digitalization and developing staff competencies. Schools' visions must encourage an effective interaction between the IT section and the instructors' committees to drive the digital experience smoothly and facilitate its primary implementation for educational purposes. The lack of interaction between the IT and instructors leads to a loss in digitalization potentials since the IT section may develop a complicated infrastructure that does not meet teachers' needs. Moreover, the complicated digital tools frustrate teachers and decrease their confidence and intentions to implement digital tools. Thus, this interaction is vital to make the IT professionals aware of teachers' needs for effective implementation and to familiarize teachers with the potential of the available digital tools for best usage.

Moreover, digitalization processes cannot be only limited to the implementation of digital technologies without pedagogical and organizational change (Pettersson, 2020). Educators play an essential role as adapters and implementers of digital learning materials (Yehya, 2019). Glover et al. (2016) claimed that digitalization that is not supported with pedagogical strategies and methods can fail to digitalize learning and enhance students' engagement and interaction. Teachers can effectively facilitate learners' use of digital tools and engage them in meaningful learning processes to support curricular goals in the process of digitalizing schools. Furthermore, it is the responsibility of teachers to teach learners about the importance of cybersecurity and how to preserve digital privacy, and to help parents be aware of the benefits and the dangers of the use of digital technology. As mentioned by Rahman et al. (2020), it is so critical for learners to be educated about the risks associated with being active in cyberspace and the strategies that stakeholders can use to promote cybersecurity education in schools. Consequently, it is critical 
to educate and empower the learning community, including parents, on the safe and responsible use of web tools and platforms so as to create a cyber-safety culture.

\section{Digital Resources and Expertise Development}

For the sake of accomplishing a strategic plan, schools require the appropriate digital tools to improve pedagogical and working practices. Accordingly, the implementation of technology in education should be improved from basic use of computer and website to the appropriate use of learning management systems (LMS) and the content management systems (CMS). It should also be upgraded so that $\mathrm{MOOC}$ providers could benefit from the widespread of social media, e-portfolio software to interact with a wider digital learning environment, and assess learners' opportunities to solve complex problems and their digital competences. According to Henderson, Selwyn, and Aston (2017), educators perhaps need to temper enthusiasm for what might be achieved through technology-enabled learning and develop better grasping of the realities of learners' encounters with digital technology. This development cannot be true without real cooperation and collaboration between the whole educational system including the school's administration, IT department, and educators. The IT section must stay aware of the relevant technological improvements and help educators to deal with the various digital resources and the free learning management systems as Microsoft Teams, Edmodo, Google Classroom, Edraak K-12, and others. Furthermore, teachers' decision of selecting a digital tool is greatly influenced by their confidence to manage the learning process with these tools (Sadaf \& Johnson, 2017). However, with all these digital tools, educators are faced with a challenge in recognizing the affordances of the digital environment. Thus, school administrations and IT departments must provide the appropriate assistance and techniques to the users to manage the digital transformation. They need to train the whole school staff and learners to have the opportunity to deal with the available digital tools. The investment in building school staff competencies lead their steps to show flexibility and freedom in their digital uptake.

\section{Learners' Motivations and Potentials}

The majority of today's learners live in a digital world. Significantly, most learners in schools now are Net-generation learners (Yehya, 2019). They are very active on their smartphones and social media platforms. Digital learners today are experiential, social learners who are expected to learn in groups to explore and discuss information and draw their conclusions (Debeş \& Oznacar, 2018). Digital learners treat the Internet and mobile phones as normal tools. They are able to use instant messaging, e-mail, and text messages, as well as to create, join, leave and rejoin groups. They are engaged in searching for information sources on the Internet and based on this, they will construct new structures and information. They enjoy enhanced interactivity with the content and connectivity with peers (Hauf, 2019). Thus, collaboration is an area of great potential for digital learners, and the use of technology to organize and integrate knowledge appears normal to them. Accordingly, digital learners simply think differently and their expectations from the school are changing radically. Consequently, traditional schools cannot fit the net-generation potentials and thus, the transition from the traditional school to digital school is a must to fit learners' enthusiasm and motivations. Today, learners can examine the usability of the implemented technology and how well it performs after being used. In addition, they can assess their abilities to project the tool's impact on learning (Yehya, 2020). So, digital learners understand the fast changes in the teaching techniques and the ways of learning with digital tools. They get the opportunities supplied by the feedback of some assessment software to assess their competencies in novel challenges and problem-solving situations. The appropriate digital assessment tools are essential to aid the evaluating process and evaluate students' cognitive processes and performance. Plickers, as an example, is one of the inventive on-line applications which collect real-time students' formative assessment data and challenge learners to answer the test questions on the spot (Yulia \& Susilowati, 2020, January). Thus, assessing learners' competencies via digital tools can be one of the most important aspects of the learning cycle that motivate learners to meaningful learning. Learners' motivation will be the catalyst for appreciating feedback, making decisions, and taking action. Accordingly, motivation may engage learners to deal with the perceived quality of technology and create their emotional connections with digitalization.

\section{Social Communities and Parents' Awareness}

Learning communities are vitally important in incubating schools' digital transformation. According to Rodriguez-Brown and Albom (1999), parental involvement is viewed as an essential component for the success of learning. There is a need to unlock the communication between parents, teachers, and learners to engage in the educational revolution. In this context, schools should benefit from the current digital era and the abundance of communication tools to spread awareness and publicize information. If parents are aware of the importance of the digital school, they will support the digitalization transformation in the school. According to Yehya (2020), the social interactive learning environment facilitates the engagement of the social committees in catering and shaping the future of the digital learning experience. Parents' committees and the learning community can raise funds to offer digital tools and solve some socioeconomic issues in the school learning environment. Moreover, a careful consideration of effective social media strategy can help schools receive support from the learning community (Andrade, 2016). Social media platforms can be a good place to connect with parents and the learning community to negotiate for constructing meaningful learning. The appropriate social media usage will engage current learners and market schools proficiently for the enrollment of future learners. Accordingly, schools should create and upgrade their websites or/and take into consideration the real advantage of the communication channels as Blogs, Facebook, Instagram, or any other social media platforms or Digital Hubs to keep the forthcoming and current parents updated with the relevant information. Moreover, schools should provide guidance and support for the appropriate use of rich social media channels and give the chance to all departments and the learning committee to be active members by interacting and sharing perspectives and experiences to support digitalization. Consequently, the social dimension in the suggested framework highlights the need to engage the learning communities in the digital transformation process to improve the academic performance for a successful educational revolution. 


\section{CONCLUSION}

Digitalization is the future for schools in this era. Nobody can repudiate the fact that the internet has brought changes in education, as well as in the general lifestyle of people globally. Accordingly, schools must reform their traditional learning environment to attain the significant benefits associated with the digital change. Schools must find ways to formulate goals and transform them into supportive infrastructures for developing performers within the organization (Pettersson, 2020).

However, the schools' digitalization process involves an educational vision and a well-equipped school with appropriate digital tools and software to ensure the effective implementation of technology and achieving a successful digital transformation. Haelermans (2017) mentioned that having access to ICT in education will not necessarily lead to an effective use of ICT in education.

Although some educators view school digitalization as a cure-all, it is important to note that technology tools do not automatically make educators more capable. IT schools' departments need to be skilled in the technology engagement learning paradigm. They need to help educators and instructors to be engaged in a digital learning environment to show their intentions and potentials to achieve their learning objectives (Pettersson, 2020). Educators are in need to adopt the exciting opportunities of digitalization to develop teaching strategies that can engage the Net-generation learners in the interactive learning process to deliver desired outcomes. Moreover, empowering learners to bring innovation in their ways of communication with the help of digital tools and techniques can be an important element in transforming traditional institutions into digital ones. Furthermore, the awareness of the parents and the learning society towards the vital role of digitalization can be an effective catalyst to encourage and develop the best practices of the digitalization model.

The research mentioned the need for a simple framework to promote digital transformation more flexibly. The researcher has looked at some digital transformation models to reform schools and thus has noticed that some changes are needed. These changes have profound implications for what models must be modified to meet the needs of facilitating digital transformation. Foremost, among those implications is the need for social communities' attitudes and beliefs to support digitalization and help users reach their potentials. According to Hernandez et al. (2011), social motivations in e-learning exert a strong positive effect on attitudes toward and usage of digital interactive tools. The usage leads to improved intentions to continue using these technologies in the future.

Other implications include the need to consider the learners' motivation and needs besides the need for appropriate tools and expert users. According to $\mathrm{Hu}$ and Zhang (2017), neglecting the needs leads to diminished motivation and satisfaction in educational technology, and this decrease in learners' satisfaction and motivation reduce the efficiency of digitalization model.

This paper recommends the suggested digitalization framework for educational revolution in traditional schools. However, additional research should be conducted regarding the impact of this framework on enhancing schools' digitalization. Researchers and educators need to examine strengths, weaknesses, opportunities, and threats (SWOT analysis) to analyze the effectiveness of the suggested dimensions of the framework on digitalizing schools and reforming education in general and in Lebanon in particular. Hence, a call was made for researchers to continue testing the suggested framework in different contexts with the intent of refining it.

\section{LIMITATIONS OF THE STUDY}

In addition to the framework's features outlined above, there are limitations inherent to the developed framework. One of the limitations is that the framework cannot be used to consider the possible benefits of school digitalization. Moreover, the framework limits the intermixed relation between its main dimensions and it reveals the transformational changes as onedirectional change for the sake of simplicity. Another limitation of this framework is its social and parental awareness component, which unfortunately can be highly varied in quality and quantity to the framework's evaluation for effective transformative changes for an educational revolution.

Funding: There was no funding for this research project.

Acknowledgements: There are no acknowledgments.

Declaration of interest: The author declares that he has no competing interests.

\section{REFERENCES}

Andrade, M. S. (2015). Effective eLearning and eTeaching-A theoretical model. In E-Learning-Instructional Design, Organizational Strategy and Management. InTech. https://doi.org/10.5772/60578

Andrade, M. S. (2016, July). Distance learning: Making connections through social networking. In Proceedings of the 3rd Annual European Conference on Social Media (pp. 9-18).

Atan, H., Keong, F. K., Aris, B., Luan, W. S., Majid, O., \& Rahman, Z. A. (2008). The Different Roles of Pedagogical Agents in the Open Source Learning Management System. Excellence in Education, 928-935.

Brown, H. D., \& Abeywickrama, P. (2010). Language assessment: Principles and classroom practices (Vol. 10). Pearson Education.

Chun, D., Kern, R., \& Smith, B. (2016). Technology in language use, language teaching, and language learning. The Modern Language Journal, 100(S1), 64-80. https://doi.org/10.1111/modl.12302 
Coccoli, M., Guercio, A., Maresca, P., \& Stanganelli, L. (2014). Smarter universities: A vision for the fast changing digital era. Journal of Visual Languages \& Computing, 25(6), 1003-1011. https://doi.org/10.1016/j.jvlc.2014.09.007

Debeş, G., \& Oznacar, B. (2018). Evaluation of the opinions of the manager, teacher, employees (secretary and servants) about school management of the digitalization and management processes of the system engineering model in education. Amazonia Investiga, 7(16), 243-253.

Fallon, C., \& Brown, S. (2016). E-learning standards: a guide to purchasing, developing, and deploying standards-conformant elearning. CRC Press.

Ghirardini, B. (2011). E-learning methodologies: A guide for designing and developing e-learning courses. Food and Agriculture Organization of the United Nations.

Glover, I., Hepplestone, S., Parkin, H. J., Rodger, H., \& Irwin, B. (2016). Pedagogy first: Realising technology enhanced learning by focusing on teaching practice. British Journal of Educational Technology, 47(5), 993-1002. https://doi.org/10.1111/bjet.12425

Haelermans, C. (2017). Digital tools in education. On usage, effects, and the role of the teacher. SNS.

Hauf, L. K. (2019). A Phenomenological Study Exploring Perceptions of the Net Generation and the Use of Visual Web 2.0 Tools in Online and On-Ground Classrooms (Doctoral dissertation, Northcentral University).

Henderson, M., Selwyn, N., \& Aston, R. (2017). What works and why? Student perceptions of 'useful' digital technology in university teaching and learning. Studies in Higher Education, 42(8), 1567-1579. https://doi.org/10.1080/03075079.2015.1007946

Hernandez, B., Montaner, T., Sese, F. J., \& Urquizu, P. (2011). The role of social motivations in e-learning: How do they affect usage and success of ICT interactive tools?. Computers in human behavior, 27(6), $2224-2232$. https://doi.org/10.1016/j.chb.2011.07.001

Holmgren, R., Haake, U., \& Söderström, T. (2017). Firefighter learning at a distance-a longitudinal study. Journal of Computer Assisted Learning, 33(5), 500-512. https://doi.org/10.1111/jcal.12196

Hu, P., \& Zhang, J. (2017). A pathway to learner autonomy: A self-determination theory perspective. Asia Pacific Education Review, 18(1), 147-157. https://doi.org/10.1007/s12564-016-9468-Z

Ilomäki, L., \& Lakkala, M. (2018). Digital technology and practices for school improvement: innovative digital school model. Research and Practice in Technology Enhanced Learning, 13(1), 25. https://doi.org/10.1186/s41039-018-0094-8

Khan, I. U., Hameed, Z., Yu, Y., \& Khan, S. U. (2017). Assessing the determinants of flow experience in the adoption of learning management systems: the moderating role of perceived institutional support. Behaviour \& Information Technology, 36(11), 1162-1176. https://doi.org/10.1080/0144929X.2017.1362475

Kryukov, V., \& Gorin, A. (2017). Digital technologies as education innovation at universities. Australian Educational Computing, 32(1), 1-16.

Lei, C. U., Wan, K., \& Man, K. L. (2013). Developing a smart learning environment in universities via cyber-physical systems. Procedia Computer Science, 17, 583-585. https://doi.org/10.1016/j.procs.2013.05.075

Lindqvist, M. H., \& Pettersson, F. (2019). Digitalization and school leadership: on the complexity of leading for digitalization in school. The international journal of information and learning technology.

Machekhina, O. N. (2017). Digitalization of education as a trend of its modernization and reforming. Revista Espacios, 38(40).

Masters, J. (2018, October). Trends in the digitalization of K-12 schools: The Australian perspective. In Seminar. net (Vol. 14, No. 2, pp. 120-131).

Niculescu, G. (2019). The Digital Technologies In Education. Annals-Economy Series, 6, 86-91.

Ordov, K., Madiyarova, A., Ermilov, V., Tovma, N., \& Murzagulova, M. (2019). New trends in education as the aspect of digital technologies. Technology, 10(2), 1319-1330.

Pettersson, F. (2020). Understanding digitalization and educational change in school by means of activity theory and the levels of learning concept. Education and Information Technologies, 1-18. https://doi.org/10.1007/s10639-020-10239-8

Pireva, K., Imran, A. S., \& Dalipi, F. (2015, August). User behaviour analysis on LMS and MOOC. In 2015 IEEE Conference on e-Learning, e-Management and e-Services (IC3e) (pp. 21-26). IEEE. https://doi.org/10.1109/IC3e.2015.7403480

Rahman, A., Malaysia, N. A., Sairi, M. T. U. K., Zizi, I. K., \& Khalid, F. (2020). The Importance of Cybersecurity Education in School. International Journal of Information and Education Technology, 10(5), 378-382. https://doi.org/10.18178/ijiet.2020.10.5.1393

Rashida, M. F. (2018). Learning Management System (LMS) in higher education institutions. Journal of Information Systems \& Information Technology (JISIT), 3(2), 15-23.

Rodriguez-Brown, F. V., Li, R. F., \& Albom, J. B. (1999). Hispanic Parents' Awareness and Use of Literacy-Rich Environments at Home and in the Community. Education and Urban Society, 32(1), 41-57. https://doi.org/10.1177/0013124599032001003

Ross, S. M. (2020). Technology infusion in K-12 classrooms: a retrospective look at three decades of challenges and advancements in research and practice. Educational Technology Research and Development, 1-18. https://doi.org/10.1007/s11423-020-097567

Ruipérez-Valiente, J. A., Muñoz-Merino, P. J., Leony, D., \& Kloos, C. D. (2015). ALAS-KA: A learning analytics extension for better understanding the learning process in the Khan Academy platform. Computers in Human Behavior, 47, $139-148$. https://doi.org/10.1016/j.chb.2014.07.002 
Sadaf, A., \& Johnson, B. L. (2017). Teachers' beliefs about integrating digital literacy into classroom practice: An investigation based on the theory of planned behavior. Journal of Digital Learning in Teacher Education, 33(4), 129-137. https://doi.org/10.1080/21532974.2017.1347534

Saha, A., \& Mukhopadhyay, P. (2016). Ranking OER providers in India: a webometric analysis. International Research: Journal of Library and Information Science, 6(1).

Schleicher, A. (2012). Preparing teachers and developing school leaders for the 21st century: Lessons from around the world. OECD Publishing. 2, rue Andre Pascal, F-75775 Paris Cedex 16, France. https://doi.org/10.1787/9789264174559-en

Selwyn, N. (2016). Digital downsides: Exploring university students' negative engagements with digital technology. Teaching in Higher Education, 21(8), 1006-1021. https://doi.org/10.1080/13562517.2016.1213229

Sharma, S. (2019). Digital Competence of Teacher Educators with respect to Open Educational Resources. Journal of the Gujarat Research Society, 21(15), 1029-1051.

Stepan, A. (2013). Massive open online courses (MOOC) Disruptive impact on higher education.

Tang, S. (2016). Digital storytelling approach in a multimedia feature writing course. Journal of Language Teaching and Research, 7(3), 572-578. https://doi.org/10.17507/jltr.0703.19

Wang, Z., \& Guo, J. (2017). Teaching and practice mode reform in digital image processing curriculum. International Journal of Information and Education Technology, 7(7), 557-560. https://doi.org/10.18178/ijiet.2017.7.7.930

Yehya, F. (2019). Impact of Computer Simulation on Students' Cognitive Achievement in Physics Courses. (Doctoral dissertation). Saint Joseph University, Beirut.

Yehya, F. (2020). Promoting Technology- Implementation Learning paradigm for online learning in secondary Education. Global Journal of Information Technology: Emerging Technologies, 10(1), 12-21. https://doi.org/10.18844/gjit.v10i1.4620

Yehya, F., Barbar, A., \& Rjeily, S. A. (2018). Diagnosing the barriers for integrating Educational Technology in Physics courses in Lebanese secondary schools. Research in Social Sciences and Technology, 3(2), 14-39. https://doi.org/10.46303/ressat.03.02.2

Yulia, Y., \& Susilowati, I. (2020, January). Digitizing learning assessment to develop students' critical thinking. In Journal of Physics: Conference Series (Vol. 1456, No. 1, p. 012053). IOP Publishing. https://doi.org/10.1088/1742-6596/1456/1/012053 